\title{
Flexural Behavior of Concrete Beam Strengthened by Near-Surface Mounted CFRP Reinforcement Using Equivalent Section Model
}

\author{
Woo-tai Jung, Jong-sup Park, Jae-yoon Kang, and Moon-seoung Keum \\ Structural Engineering Research Institute, Korea Institute of Civil Engineering and Building Technology, Goyang, Republic of Korea \\ Correspondence should be addressed to Woo-tai Jung; woody@kict.re.kr
}

Received 26 August 2016; Accepted 4 December 2016; Published 12 February 2017

Academic Editor: Carlo Santulli

Copyright (C) 2017 Woo-tai Jung et al. This is an open access article distributed under the Creative Commons Attribution License, which permits unrestricted use, distribution, and reproduction in any medium, provided the original work is properly cited.

\begin{abstract}
FRP (fiber reinforced polymer) has found wide applications as an alternative to steel rebar not only for the repair and strengthening of existing structures but also for the erection of new structures. Near-surface mounted (NSM) strengthening was introduced as an alternative of externally bonded reinforcement (EBR) but this method also experiences early bond failure, which stresses the importance of predicting accurately the bond failure behavior in order to evaluate precisely the performance of NSM reinforcement. This study proposes the equivalent section model assuming monolithic behavior of the filler and CFRP reinforcement. This equivalent section model enables establishing a bond failure model applicable independently of the sectional shape of the CFRP reinforcement. This so-derived bond failure model is then validated experimentally by means of beams flexure-strengthened by NSM CFRP reinforcements with various cross-sections. Finally, analytical analysis applying the bond failure model considering the equivalent section and defined failure criteria is performed. The results show the accuracy of the prediction of the failure mode as well as the accurate prediction of the experimental results regardless of the sectional shape of the CFRP reinforcement.
\end{abstract}

\section{Introduction}

Despite its excellence as construction material, concrete degrades with time and the serviceability deteriorates following the ongoing performance loss of the concrete member and the material itself caused by environmental actions. The width of the cracks developed in concrete enlarges gradually with time and favors the penetration of impurities, which accelerate the degradation of the structure. Steel plate bonding, external tendons prestressing, and FRP (fiber reinforced polymer) bonding are some of the common strengthening methods for degraded concrete structures. Steel plate bonding offers poor workability on site due to its heavy weight and is susceptible to corrosion. External tendons prestressing can improve the serviceability by controlling the cracks and restoring the deflection but requires anchoring devices that are designed to have substantial size to meet the tensile strength of the reinforcement. All three methods present the inconvenience of being vulnerable to external damage because of external reinforcements factual exposure at the surface of the reinforced section. Besides, FRP bonding improves the performance of the structure by bonding the CFRP (carbon fiber reinforced polymer) sheet or plate on the tensile face of the concrete member. Owing to the lightweight, corrosion-resistant, and high strength properties of CFRP, FRP bonding is gaining wider applications as an alternative to steel plate bonding [1-6].

The structure strengthened by externally bonded CFRP sheet or plate experiences bond failure of the interface between the FRP reinforcement and concrete, which makes the CFRP reinforcement unable to develop $100 \%$ of its capacity. The risk of bond failure increases with shorter reinforced length and larger amount of reinforcement. Also, this risk depends sensitively on the skill of the technician executing the strengthening work [2]. Another drawback of the external bonding is the exposure of the reinforcement, which increases the risk of damage caused by vehicle impact or fire and makes it difficult to achieve strengthening effect without 
sufficient protection. Accordingly, Near-Surface Mounted (NSM) strengthening was introduced to minimize such problems and improve the utilization of the reinforcing material [2]. NSM strengthening using CFRP reinforcement started since 1990s and designates the strengthening method embedding the CFRP reinforcement and the filler inside the slot dug in the tensile zone of the concrete cover. The NSM strengthening is known to reduce the tasks executed on site compared to the external bonding and to decrease the effects of early bond failure $[3,4]$.

Similarly to external bonding, NSM strengthening also experiences bond failure. This topic is being studied until now and necessitates deeper investigation since different bond failure models were proposed according to the sectional shape of the reinforcement or stochastic data. There is a need is thus to provide a bond failure model for each shape of CFRP reinforcement to predict the flexural behavior of the member strengthened by NSM reinforcement (NSMR) [58]. Bond failure may theoretically occur in diverse manners like the interfacial failure between the CFRP reinforcement and filler, the failure of the filler-concrete interface, and so on. Because the bond failure induced experimentally may be different than that predicted theoretically, the bond failure model should rely on actual failure patterns. Accordingly, the proposed bond failure model should be applicable regardless of the sectional shape of the CFRP reinforcement based upon the close analysis of the bond failure occurring actually in the flexure-strengthened behavior.

This study intends to propose a bond failure model considering the equivalent section through the analysis of the failure patterns of specimens flexure-strengthened by NSM CFRP reinforcement and to validate this model with regard to the flexural behavior of NSM-strengthened specimens with various CFRP reinforcement shapes. Other studies have deficiencies such as complicated analysis and various failures with FRP shapes because they have used the data which is not flexural test, but pull-out test. This study offers new failure model with equivalent section which results from failure mode of flexural test.

\section{Major Failure Modes of Flexure- Strengthened Specimens by NSMR}

The common failure modes experienced by the RC (reinforced concrete) member strengthened by NSM CFRP are various like failure at the interface FRP-filler, cohesive failure on filler, failure at the interface filler-concrete, and cohesive failure on concrete [8]. Since bond failure is an important factor affecting the performance of the member, studies were carried out to predict experimentally and analytically the bond failure characteristics. Even if bond failure by pull-out test occurs in various ways like failure of CFRP reinforcement-filler interface, inside the filler, or of the filler-concrete interface, the bond failure of the flexurestrengthened member by NSM reinforcement may lack diversity compared to that of the pull-out test [4]. Accordingly, there is a need is to examine the major failure modes through

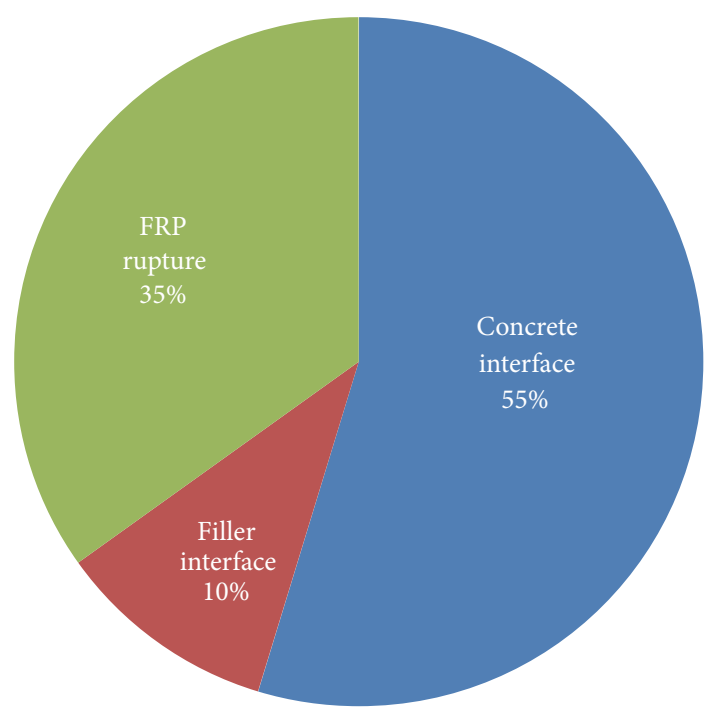

FIgURE 1: Distribution of the types of failure mode of flexurestrengthened concrete beams (2004-2016, 106 beams strengthened with NSM reinforcement) [5-8, 10, 23-40].

bending test in order to evaluate the flexural behavior of the NSM reinforcement.

The investigated results until 2016 on the failure modes observed in 106 concrete beams flexure-strengthened by NSM FRP reinforcement and shown in Figure 1 reveal that failure occurred mainly by rupture of the FRP reinforcement and failure of the filler-concrete interface (including the concrete cover). This indicates that about $90 \%$ of the failures experienced by the flexure-strengthened members by NSM FRP occur through the rupture of FRP or the failure of the concrete interface, which represent the major failure modes determining the strengthened performance of the flexural members.

This means that the bond failure in NSM strengthening depends on cohesive concrete around the slot because strength of cohesive filler is better than that of cohesive concrete generally. Therefore the filler-CFRP reinforcement ensemble behaves like a unique reinforcement. Accordingly, this study assumes the filler-CFRP reinforcement ensemble as an equivalent section to propose the bond failure model. The equivalent section illustrated in Figure 2 is defined as the section including the sections of the filler and reinforcement and behaving monolithically. Under this assumption, the stress developed at the filler-reinforcement interface is transferred to the filler-concrete interface by means of the filler, which will enable us to propose a bond failure model independent of the sectional shape of the reinforcement.

\section{Proposal of Bond Failure Model}

The following assumptions are adopted to establish the bond failure model applying the equivalent section derived above. First, bond failure occurs at the concrete-equivalent section interface. Second, the shear force that occurred at the CFRPfiller interface is transferred to the filler-concrete interface. 


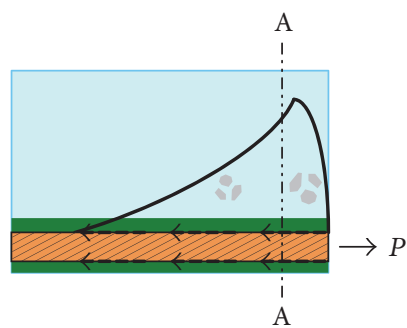

Section A-A
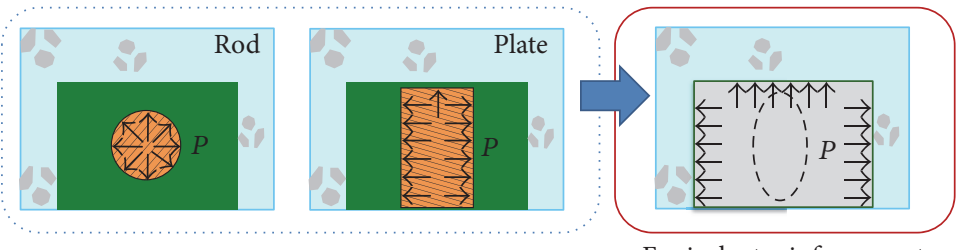

Equivalent reinforcement

FIGURE 2: Concept of equivalent section.
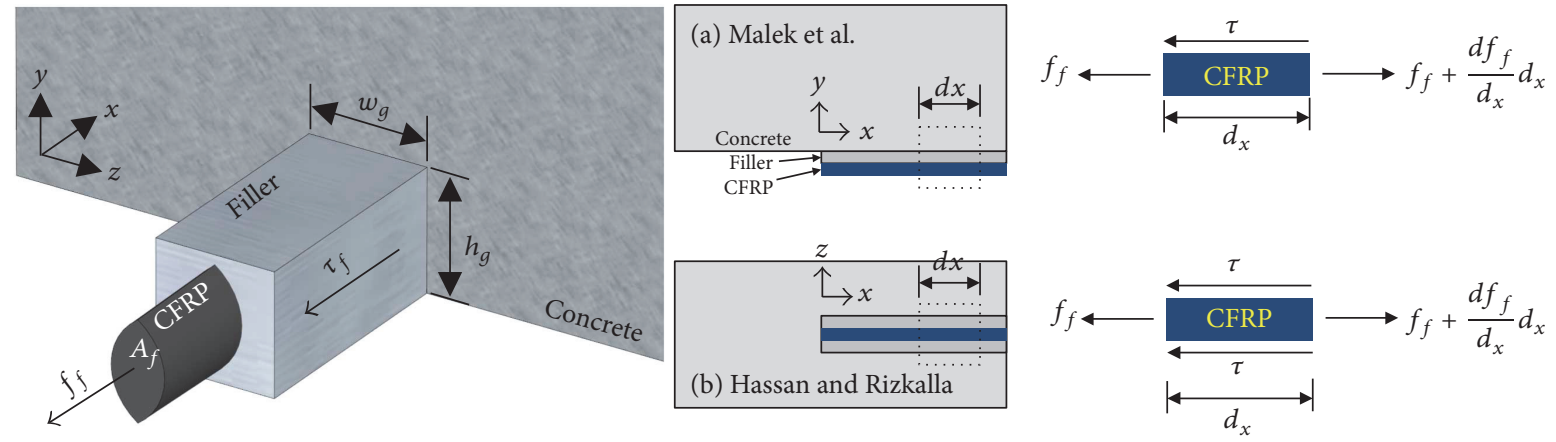

FIGURE 3: Shear stress developed at the interface $[5,9]$.

Third, the filler is considered only as a mean to transfer the shear force and the deformation of the filler is ignored (see (1)).

Based upon these assumptions, the equilibrium of the forces acting on the infinitesimal element $d x$ of Figure 3(b) can be expressed as follows:

$$
A_{f} d f_{f}=\tau_{c}\left(2 h_{g}+w_{g}\right) d x
$$

where $\tau_{c}$ is shear stress developed at the epoxy-concrete interface; $h_{g}$ is depth of slot; $w_{g}$ is width of slot; and $A_{f}$ is cross-sectional area of CFRP reinforcement.

Rearranging (1) with respect to $\tau_{c}$ gives (2). The formulations derived by Malek et al. [9] and Hassan and Rizkalla [5] from the infinitesimal element shown in Figure 3 are expressed in (3) and (4), respectively.

$$
\begin{aligned}
& \tau_{c}=\frac{A_{f}}{\left(2 h_{g}+w_{g}\right)} \frac{d f_{f}}{d x} \\
& \tau_{c}=\frac{d f_{f}}{d x} t_{f}[9] \\
& \tau_{c}=\frac{1}{2} \frac{d f_{f}}{d x} t_{f}[5],
\end{aligned}
$$

where $t_{f}$ is thickness of CFRP plate and $f_{f}$ is tensile stress of CFRP plate.

The shear stress $\tau_{c}$ proposed in this study for the infinitesimal element is expressed in terms of the dimensions of the slot and the cross-sectional area of the CFRP reinforcement since the equivalent section is assumed. The formulations for $\tau_{c}$ provided in (3) and (4) are expressed in terms of the dimensions of the CFRP reinforcement. Equation (5) reformulates $\tau_{c}$ of (2) proposed in this study for the 4-point loading condition shown in Figure 4. The derivation of (5) is skipped here since it is similar to that reported by Hassan and Rizkalla [5]:

$$
\begin{aligned}
\tau_{c}=\frac{A_{f}}{\left(2 h_{g}+w_{g}\right)}\left(\frac{n P l_{0} y_{e}}{I_{e}} \phi e^{-\phi x}+\frac{n P y_{e}}{I_{e}}\right), & \\
\phi^{2}=\frac{\left(2 h_{g}+w_{g}\right) G_{a}}{A_{f} t_{a} E_{f}}, & \\
& n=\frac{E_{f}}{E_{c}},
\end{aligned}
$$

where $P$ is applied load; $l_{0}$ is distance from support to end of reinforcement; $x$ is distance from end of reinforcement; $y_{e}$ is distance from reinforcement to neutral axis; $I_{e}$ is effective moment of inertia; $E_{f}$ is elastic modulus of CFRP reinforcement; $E_{c}$ is elastic modulus of concrete; $t_{a}$ is thickness of epoxy; and $G_{a}$ is shear elastic modulus of epoxy.

3.1. Failure Criteria. It is primordial to establish failure criteria to simulate bond failure using the analytical model. In particular, the bond failure of the flexure-strengthened specimens by NSM reinforcement is similar to that of the external bonding since it occurs at the concrete-filler interface and not in the filler nor at the reinforcement-filler interface $[5,10]$.

A survey of the research on the bond characteristics of External Bonding Reinforcement (EBR) reveals that the 


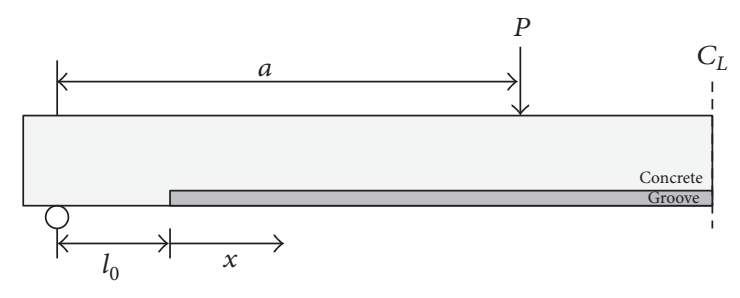

FIGURE 4: Four-point loading.

bond failure criterion at the end of the reinforcement is set as the concrete failure coefficient (flexure-tensile strength), which when exceeded means that failure has occurred $[9,11$, 12]. Moreover, since bond failure occurs along the concrete surface, many researchers define the strength of the concrete surface as the interfacial bond failure criterion $[13,14]$. The bond failure occurring at the concrete interface is closely related to the cracking strength of concrete and is assumed to occur when the shear stress developed at the concrete interface exceeds the cracking strength of concrete [12].

Accordingly, since cracking at the concrete interface has decisive effect on the propagation of the cracks and on the bond failure, this study adopts the concrete flexuretensile strength (failure coefficient) proposed by numerous researchers like Malek et al. [9] and Tumialan et al. [12] as failure criterion. The cracking stress of normal concrete is calculated as the following failure coefficient (flexure-tensile strength) [15] and it is assumed that bond failure occurs when the value of the cracking stress exceeds the failure criterion of

$$
\tau_{\max }=f_{r}=0.63 \sqrt{f_{c k}}(\mathrm{MPa})=7.5 \sqrt{f_{c k}}(\mathrm{psi})
$$

3.2. Concrete Material Model. The stress-strain curve of concrete is represented using the parabolic material model shown in Figure 5(a). This model is assumed to exhibit nonlinear elastic behavior with a parabolic shape until the ultimate compressive strain $\left(\varepsilon_{c u}\right)[16]$.

$$
f_{c}=f_{c k}\left[\frac{2 \varepsilon_{c}}{\varepsilon_{c}^{\prime}}-\left(\frac{\varepsilon_{c}}{\varepsilon_{c}^{\prime}}\right)^{2}\right],
$$

where $f_{c}$ is stress of concrete; $f_{c k}$ is compressive strength of concrete; $\varepsilon_{c}$ is strain of concrete; $\varepsilon_{c}^{\prime}$ is strain when the concrete stress $f_{c}$ reaches the compressive strength $f_{c k}$. The value of $\varepsilon_{c}^{\prime}$ is assumed to be 0.002 in this study. Note that the ultimate compressive strain of concrete is assumed to 0.003 .

3.3. Material Model of Steel Reinforcement. As shown in Figure 5(b), the stress-strain curve of the steel reinforcement is assumed to be bilinear exhibiting linear elastic behavior before the yield stress $\left(f_{y}\right)$ and perfect plastic behavior beyond the yield stress. The elastic modulus in the plastic region is set as $E_{s}^{\prime}=0.01 E_{s}[17]$.

$$
\begin{aligned}
& f_{s}=E_{s} \varepsilon_{s} \quad \text { for } \varepsilon_{s} \leq \varepsilon_{y} \\
& f_{s}=f_{y}+E_{s}^{\prime}\left(\varepsilon_{s}-\varepsilon_{y}\right) \quad \text { for } \varepsilon_{s} \geq \varepsilon_{y},
\end{aligned}
$$

where $f_{s}$ is stress of steel rebar; $\varepsilon_{s}$ is strain of steel rebar; $\varepsilon_{y}$ is yield strain of steel rebar; $E_{s}$ is elastic modulus of steel rebar; and $E_{s}^{\prime}$ is elastic modulus in plastic zone.

3.4. Material Model of CFRP Reinforcement. The stress-strain curve of CFRP reinforcement shown in Figure 5(c) assumes linear elastic behavior until rupture. In Figure 5(c), $f_{f u}$ designates the rupture stress of the CFRP reinforcement and $\varepsilon_{f u}$ is the rupture strain of the CFRP reinforcement.

$$
f_{f}=E_{f} \varepsilon_{f},
$$

where $f_{f}$ is stress of CFRP reinforcement; $\varepsilon_{f}$ is strain of CFRP reinforcement; and $E_{f}$ is elastic modulus of CFRP reinforcement.

\section{Computation of Deflection}

The deflection of an ordinary RC member can be classified into three zones delimited by the initiation of cracks and the yielding of the tensile rebar. The effective moment of inertia $\left(I_{e}\right)$ is calculated according to this classification and applied in the formula computing the deflection [18]. In general, the whole section is considered to be effective prior to the initiation of cracks and the corresponding moment of inertia of the whole section $\left(I_{g}\right)$ is applied. For the zone after cracking and before yielding of the tensile rebar, the effective moment of inertia of Branson [19] is adopted, and, for the zone after yielding of the tensile rebar, the cracked section moment of inertia $\left(I_{c r}\right)$ is used. In this study, the flexural rigidity is calculated by applying the moment-curvature curve from early loading and used to compute the deflection per loading stage $[19,20]$. The curvature $(\phi)$ at an arbitrary loading stage is computed as follows using the concrete strain $\left(\varepsilon_{c}\right)$ and neutral axis $(c)$.

$$
\phi=\frac{\varepsilon_{c}}{c} .
$$

Here, the flexural rigidity $(\mathrm{EI})_{e}$ at any loading stage can be expressed as follows from the moment-curvature $(M-\phi)$ relation:

$$
(\mathrm{EI})_{e}=\frac{M}{\phi}
$$

Once the flexural rigidity is calculated, the deflection $(\Delta)$ at midspan can be computed as follows according to the loading condition that is 4-point loading here:

$$
\Delta=\frac{\mathrm{Pa}}{24(\mathrm{EI})_{e}}\left(3 L^{2}-4 a^{2}\right) .
$$

\section{Section Analysis of Beam Strengthened by NSMR}

Section analysis is conducted using the strain compatibility condition and equilibrium of the forces to predict the flexural behavior of the reinforced specimens. The moment-curvature distribution of ordinary RC specimens can be classified into 


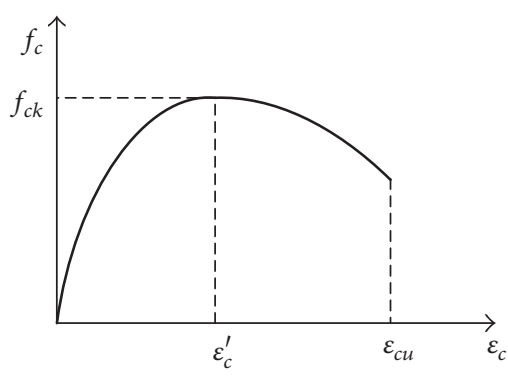

(a) Concrete

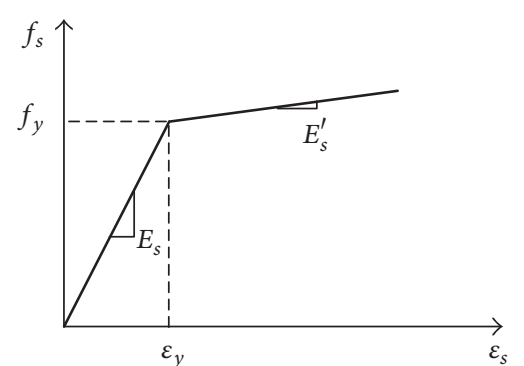

(b) Steel reinforcement

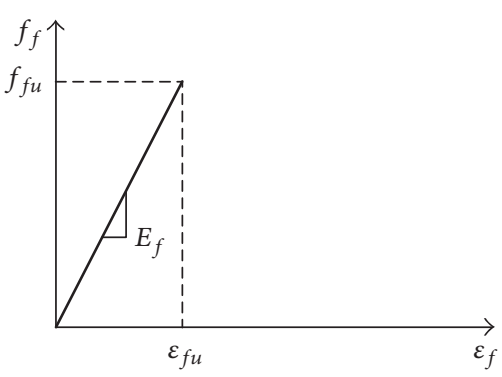

(c) CFRP reinforcement

Figure 5: Material models.

three zones delimited by the initiation of cracks in concrete and the yielding of rebar. Therefore, the section analysis is performed considering three different cases that are as follows: the precracking stage when the acting moment $M_{a}$ due to the load is smaller than the cracking moment; the preyielding stage after cracking and before yielding of the rebar; and the postyielding case $[14,20]$. The calculation for each case uses the equilibrium of the forces and moments. Figure 6 describes the strain and stress distributions in each case.

(a) Precracking stage: $0 \leq M_{a} \leq M_{c r}$.

$$
\begin{aligned}
& \frac{1}{2} f_{c} b c+A_{s}^{\prime} f_{s}^{\prime}-\frac{1}{2}(h-c) f_{c t} b-A_{s} f_{s}-A_{f} f_{f e}=0 \\
& M_{a} \\
& \quad=\frac{1}{3} f_{c t} b h(h-c)+A_{s} f_{s}\left(d_{s}-\frac{1}{3} c\right) \\
& \quad+A_{f} f_{f e}\left(d_{f}-\frac{1}{3} c\right)-A_{s}^{\prime} f_{s}^{\prime}\left(\frac{1}{3} c-d_{s}^{\prime}\right) .
\end{aligned}
$$

(b) Preyielding stage: $M_{c r} \leq M_{a} \leq M_{y}$.

$$
\begin{aligned}
& \alpha_{1} \beta_{1} f_{c k} b c+A_{s}^{\prime} f_{s}^{\prime}-A_{s} f_{s}-A_{f} f_{f e}=0 \\
& M_{a} \\
& \quad=A_{s} f_{s}\left(d_{s}-\frac{1}{2} \beta_{1} c\right)+A_{f} f_{f e}\left(d_{f}-\frac{1}{2} \beta_{1} c\right) \\
& \quad-A_{s}^{\prime} f_{s}^{\prime}\left(\frac{1}{2} \beta_{1} c-d_{s}^{\prime}\right) .
\end{aligned}
$$

(c) Postyielding stage: $M_{y} \leq M_{a} \leq M_{u}$.

$$
\begin{aligned}
& \alpha_{1} \beta_{1} f_{c k} b c+A_{s}^{\prime} f_{s}^{\prime}-A_{s}\left[f_{y}+E_{s}^{\prime}\left(\varepsilon_{s}-\varepsilon_{y}\right)\right]-A_{f} f_{f e} \\
& \quad=0 \\
& M_{a} \\
& \quad=A_{s}\left[f_{y}+E_{s}^{\prime}\left(\varepsilon_{s}-\varepsilon_{y}\right)\right]\left(d_{s}-\frac{1}{2} \beta_{1} c\right) \\
& \quad+A_{f} f_{f e}\left(d_{f}-\frac{1}{2} \beta_{1} c\right)-A_{s}^{\prime} f_{s}^{\prime}\left(\frac{1}{2} \beta_{1} c-d_{s}^{\prime}\right) .
\end{aligned}
$$

5.1. Determination of Bond Failure. The common failure modes in NSMR with 1 line of reinforcement are known to be the rupture of the CFRP reinforcement and the bond failure of the concrete-filler interface (bond model I). When NSMR is done with more than 1 line of reinforcement, the failure mode varies according to the interval between the slots or the distance to the corners. If the space of slots is sufficiently wide or the distance from slot to the corners is larger than a definite value, rupture of the CFRP reinforcement or bond failure of the concrete interface may occur similarly to the 1-line NSMR (bond model II-1). However, when it is not the case, failure may occur not only through the concrete interface but also by failure of concrete between the slots or spalling of the concrete between the slots and the corners (bond model II2). Accordingly, this study simplifies the failure pattern as shown in Figure 7 to simulate analytically such failures. In Figure 7, even if different from the bond failure of the corner concrete only, the failure of two lines of reinforcement is considered to occur through the bond failure between the slots. In such case, this simplified pattern appears to remain applicable if failure of the corners occurs after the bond failure between the slots. During the section analysis, since it is difficult to model the amount of reinforcement in the 2 lines, the simplification assumes that the 2 lines of reinforcement and the filler behave as one unique reinforcement and filler ensemble as shown in Figure 7. Accordingly, in case of NSMR with 2 lines of reinforcement, the width of the slot, the amount of reinforcement, and the width of the filler are doubled to compute the shear stress developed at the end of the reinforcement.

5.2. Calculation Procedure. In order to predict the nonlinear behavior of the specimens strengthened by NSMR using CFRP, the analysis is conducted in three different stages. Figure 8 presents the flowchart of the calculation procedure adopted in the analysis. The calculation procedure determines the load, the position of the neutral axis, the strain in each material and the deflection using the strain compatibility condition, the constitutive equations of each material, and the equilibrium of the internal forces by increasing the strain according to the material model of the steel rebar. Final failure is decided at bond failure using the bond failure model proposed in this study when the shear stress developed at the end of the CFRP reinforcement exceeds the maximum 


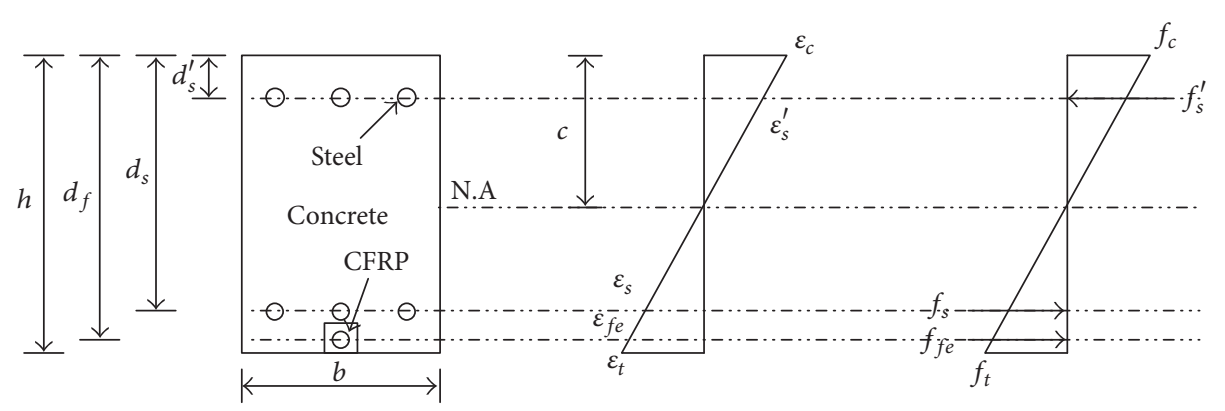

(a)

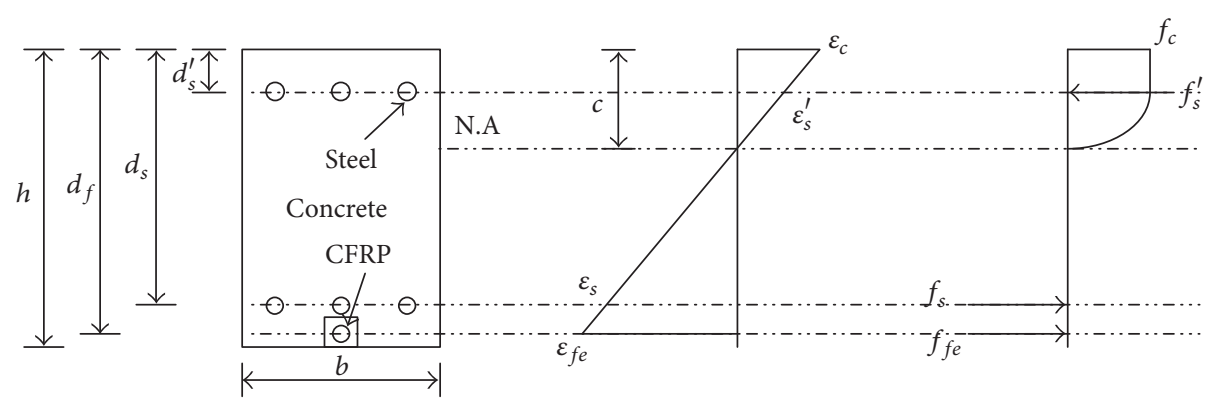

(b)

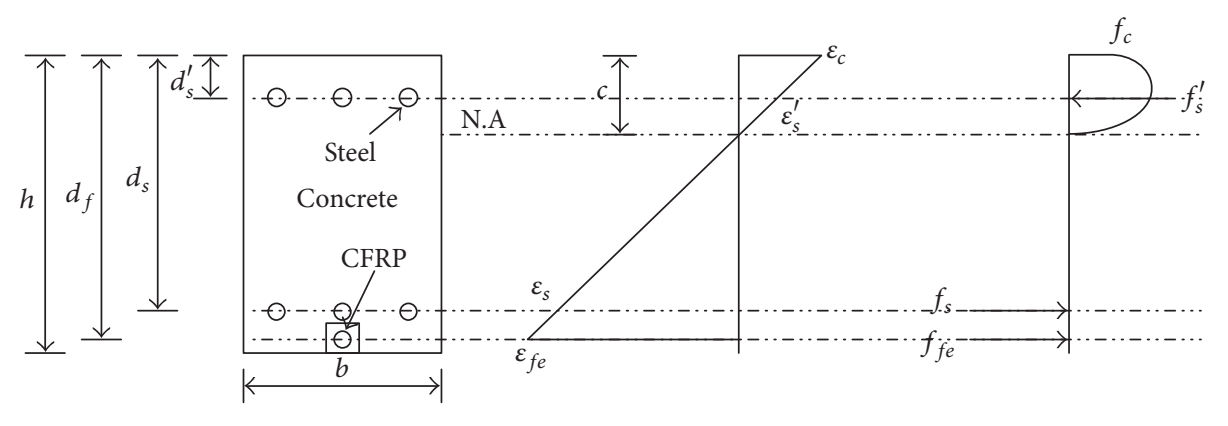

(c)

FIGURE 6: Strain and stress distributions per analysis stage.

shear strength, at compressive failure of concrete when the compressive strain at the top of concrete exceeds 0.003 and at rupture of the reinforcement when the rupture strain of the CFRP reinforcement is exceeded.

\section{Validation Test of Bond Failure Model for NSMR}

6.1. Test Variables. When the filler and FRP reinforcement behave as an equivalent reinforcement, the equivalent reinforcement can be modeled using the equivalent section during the section analysis. In such case, it is acceptable to skip the consideration of the concrete-filler interface and filler-FRP reinforcement interface. Therefore, it is necessary to check the behavior of this equivalent reinforcement by examining the failure mode of beams flexure-strengthened by FRP reinforcements exhibiting various sectional shapes. To that goal, a series of tests were conducted to validate the behavior of the equivalent section using CFRP reinforcements presenting rectangular, round, and trapezoidal shapes.
It is necessary to understand the arrangement details of the reinforcement in the reinforced section to mount it at the bottom of the beam. To that goal, two lines of reinforcement are arranged as shown in Figure 9 and the test variables are set as the spacing between the two lines $(S=60 \mathrm{~mm}$ and $2 S=120 \mathrm{~mm})$ and as the embedded depth $(25 \mathrm{~mm}$ and $15 \mathrm{~mm}$ ) to evaluate their influence on the section failure mode and strengthening effect. The same reinforced length of $2,700 \mathrm{~mm}$ is applied in all the specimens. Table 1 summarizes the designation of the specimens with the test variables. Figure 9 depicts the cross-section of each of the specimens designated in Table 1 and corresponding reinforced areas $\left(A_{f}\right)$.

6.2. Fabrication of Specimens Strengthened by NSMR. A total of 9 specimens were fabricated as shown in Figure 10 to verify the reliability of the bond failure model used in the analysis. The fabrication used ready-mixed concrete with design strength of $27 \mathrm{MPa}$. D10 SD40 tensile rebar were arranged with reinforcement ratio of 0.0041 and three D13 


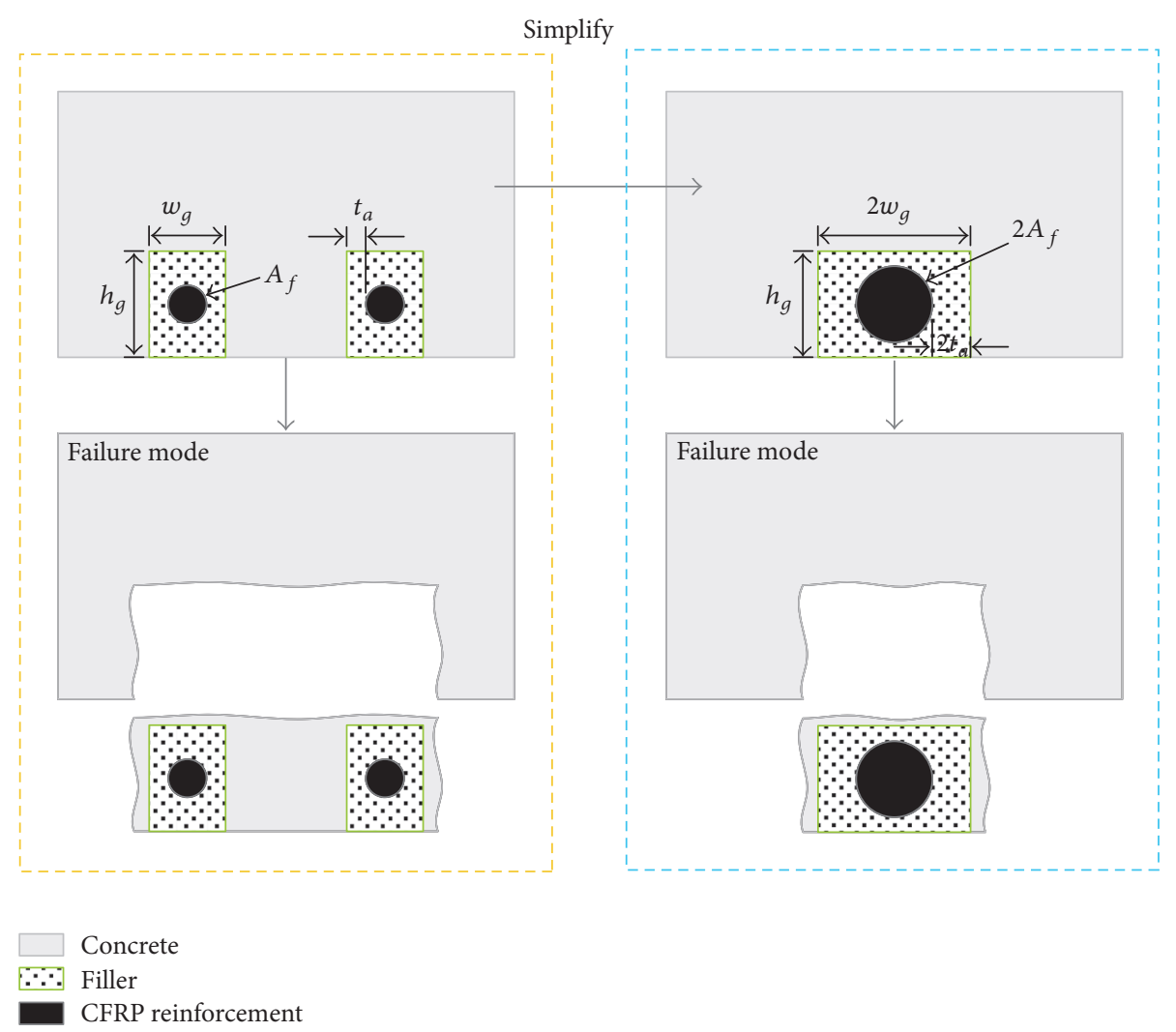

FIGURE 7: Simplification of failure mode of 2-line reinforcement [bond model II-2].

TABLE 1: Designation of specimens and corresponding test variables.

\begin{tabular}{|c|c|c|c|c|c|}
\hline Specimen & $\begin{array}{c}\text { CFRP area } \\
\left(\mathrm{mm}^{2}\right)\end{array}$ & CFRP type & Slot depth (mm) & CFRP cross-sectional shape & $\rho_{f}$ \\
\hline CONTROL & - & - & - & Nonstrengthened & - \\
\hline R-TR-10 & 35.0 & Rod & 25 & Trapezoidal & 0.0003 \\
\hline R-PL-15 & 21.0 & Strip & 15 & Rectangular & 0.0003 \\
\hline R-PL-25 & 35.0 & Strip & 25 & Rectangular & 0.0005 \\
\hline R-RD-9 & 63.6 & Rod & 25 & Round & 0.0007 \\
\hline R-PL-25*2-S & 70.0 & Strip & 25 & Rectangular & 0.0010 \\
\hline R-PL- $25^{*} 2-2 S$ & 70.0 & Strip & 25 & Rectangular & 0.0010 \\
\hline R-RD-9*2-S & 127.2 & Rod & 25 & Round & 0.0014 \\
\hline R-RD-9*2-2S & 127.2 & Rod & 25 & Round & 0.0014 \\
\hline
\end{tabular}

compressive reinforcements were disposed. D10 shear reinforcements were disposed at spacing of $100 \mathrm{~mm}$ to prevent shear failure. Strain gauges (T1, T2, B1, and B3) were bonded at midspan on the upper and lower steel reinforcements and at the quarters (B2, B4) on the lower rebar to measure the strain of the reinforcements according to loading (Figure 10).

The reinforcement ratio of the CONTROL beam was set to 0.0041 between the minimum ratio of 0.0032 and maximum ratio of 0.033 to induce ductile failure and not compressive failure of concrete and to increase the difference in the reinforcing performance. The equivalent reinforcement ratio of FRP is calculated using (16) for the conversion of the
FRP reinforcement ratio into steel reinforcement ratio and the corresponding values are listed in Table 1.

$$
\rho_{f}=\frac{A_{f}}{b d_{f}} \times \frac{E_{f}}{E_{s}},
$$

where $A_{f}$ is cross-sectional area of CFRP reinforcement $\left(\mathrm{mm}^{2}\right) ; b$ is width of section $(\mathrm{mm}) ; d_{f}$ is effective depth $(\mathrm{mm})$; $E_{f}$ is elastic modulus of CFRP reinforcement $(\mathrm{MPa})$; and $E_{s}$ is elastic modulus of steel reinforcement $(\mathrm{MPa})$.

Similarly to the CONTROL beam, the flexurestrengthened specimens are reinforced by an amount of 


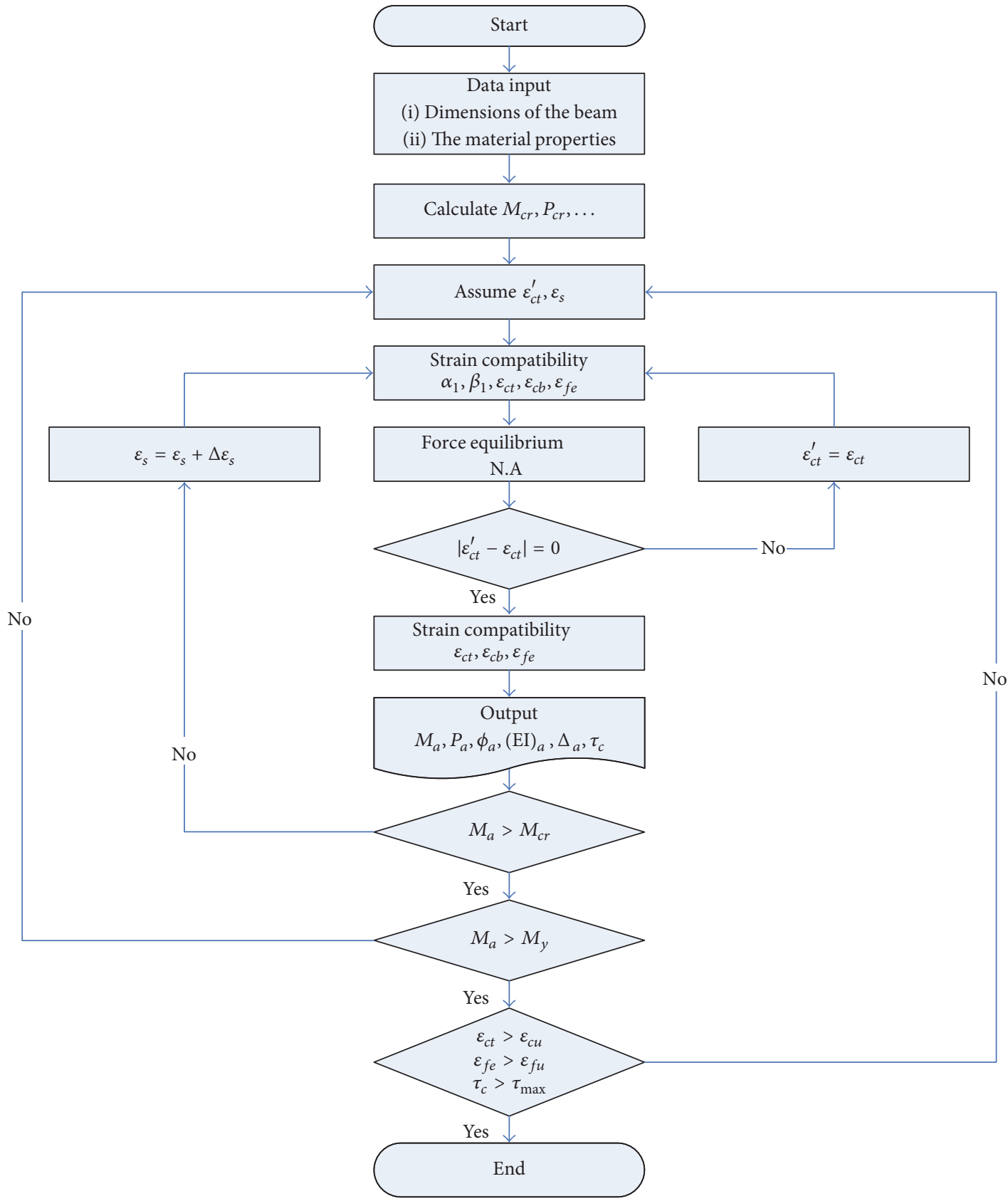

FIGURE 8: Flowchart of calculation procedure.

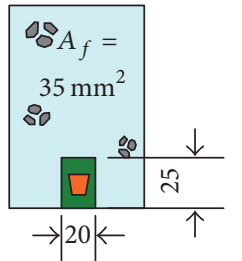

R-TR-10

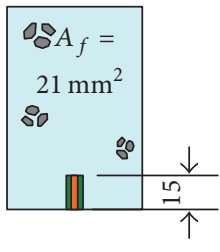

R-PL-15

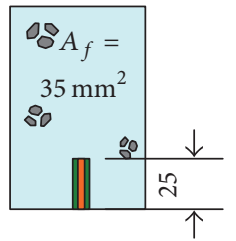

R-PL-25
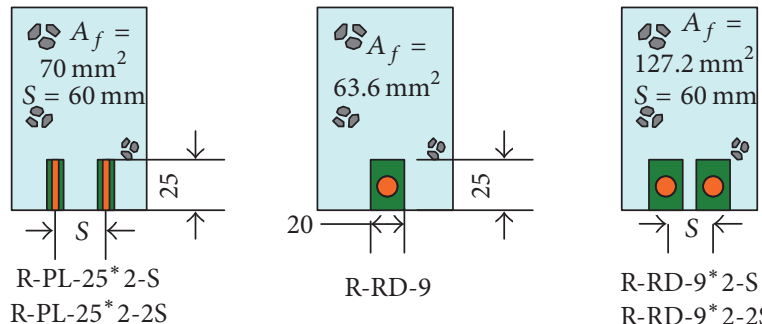

FIGURE 9: Cross-section of specimens strengthened by NSMR [unit: mm]. 


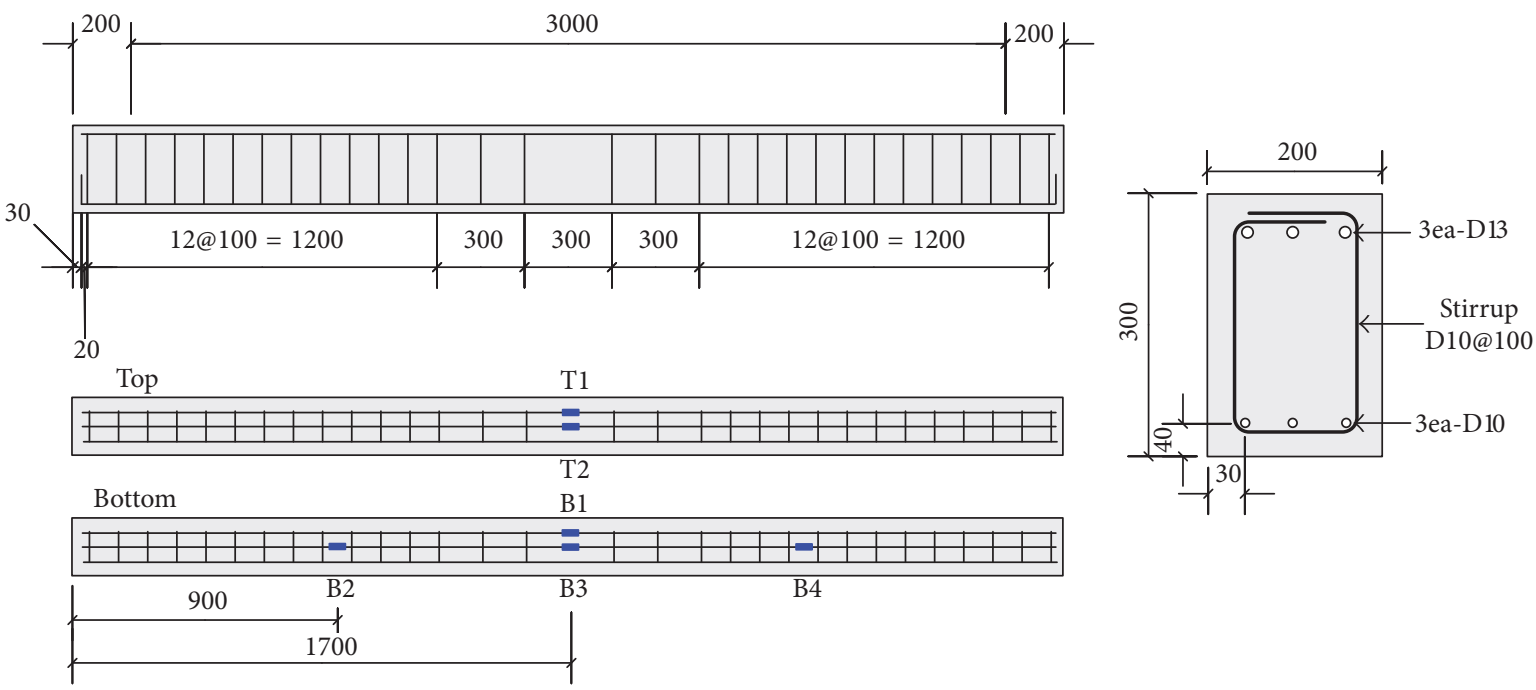

FIgURE 10: Dimensions and details of specimens [unit: $\mathrm{mm}$ ].

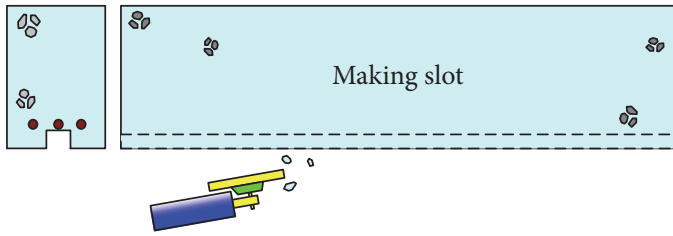

(a)

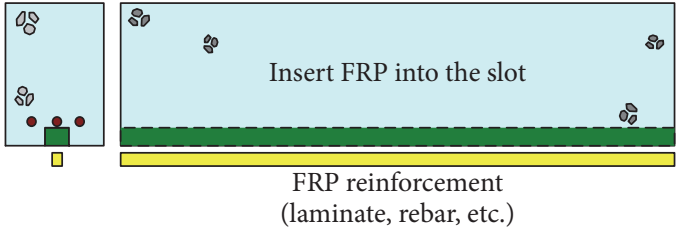

(c)

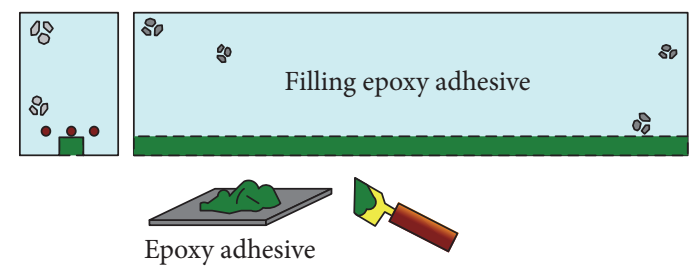

(b)

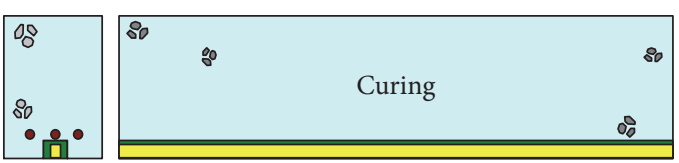

(d)

FIGURE 11: Specimen strengthening process by NSMR.

reinforcement smaller than the maximum reinforcement ratio to induce ductile failure. For the NSM strengthening, a slot was grinded using a grinder at midspan on the bottom of the beam and the fine dust was removed by air-brushing. Then, primer was applied in the slot and cured for more than 1 day. The filler for NSMR adopted an epoxy matrix mixed with hardener at a proportion of $2: 1$ and was applied in the slot. The reinforcement was finally embedded with respect to the considered test variable and curing was conducted for more than 3 days prior to the test (Figure 11).

Table 2 summarizes the material properties. The rectangular and trapezoidal CFRP reinforcements present smooth surface without particular surface treatment whereas the round CFRP reinforcement is deformed by wrapping the surface by fabrics.

6.3. Loading and Measurement Methods. Four-point loading test was conducted using UTM (Universal Testing Machine) with capacity of $980 \mathrm{kN}$ (Figure 12). Loading was applied

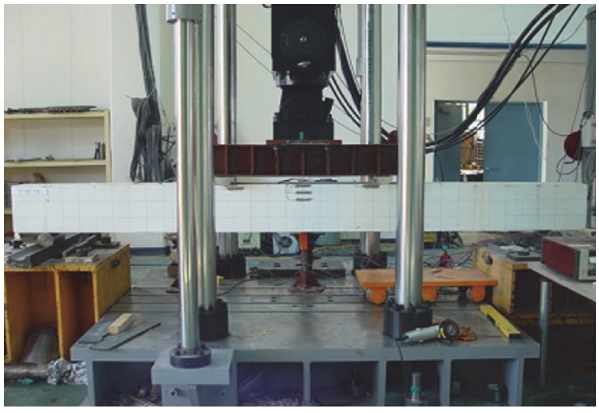

FIgURE 12: Test setup.

through displacement control at speed of $0.02 \mathrm{~mm} / \mathrm{s}$ until a displacement of $15 \mathrm{~mm}$ and speed of $0.05 \mathrm{~mm} / \mathrm{s}$ beyond that displacement until failure. The data were measured at intervals of $1 \mathrm{~s}$ and recorded using a static data logger and a computer. 


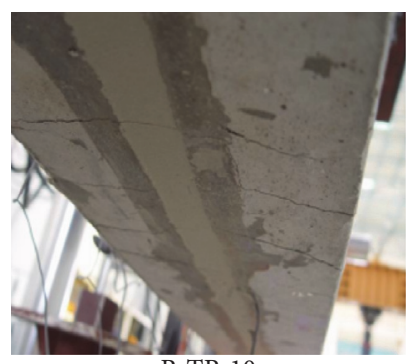

R-TR-10

CFRP rupture

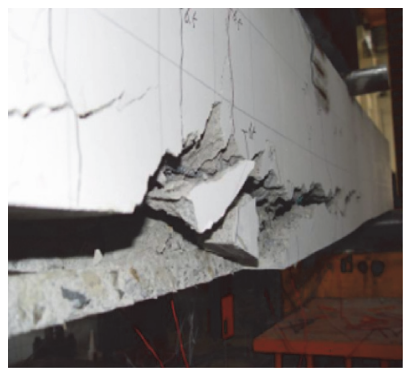

R-PL- $25^{*} 2-\mathrm{S}$

Bond failure

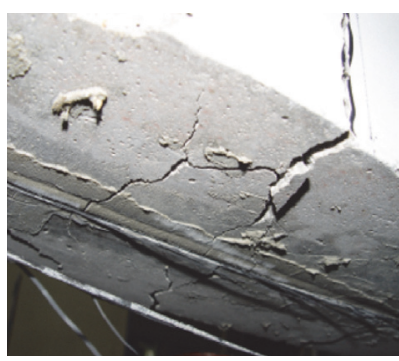

R-PL-15

CFRP rupture

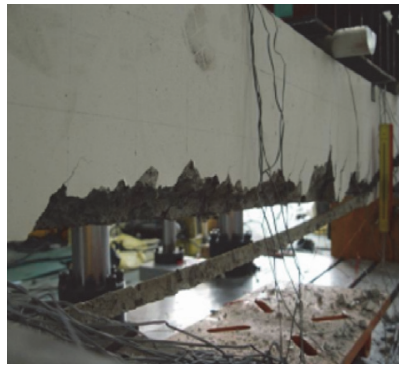

R-PL-25*2-2S

Bond failure

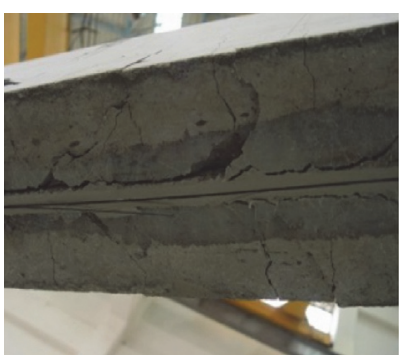

R-PL-25

Bond failure

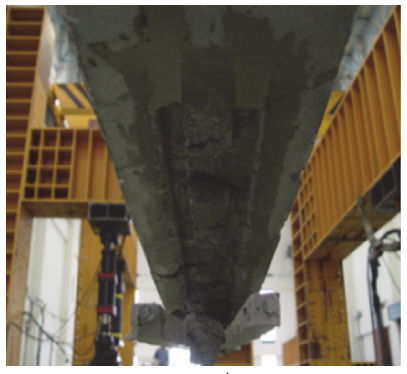

$\mathrm{R}-\mathrm{RD}-9^{*} 2-\mathrm{S}$

Bond failure

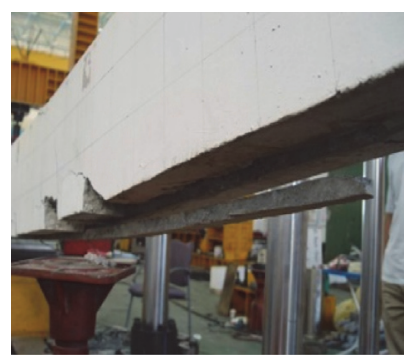

R-RD-9

Bond failure

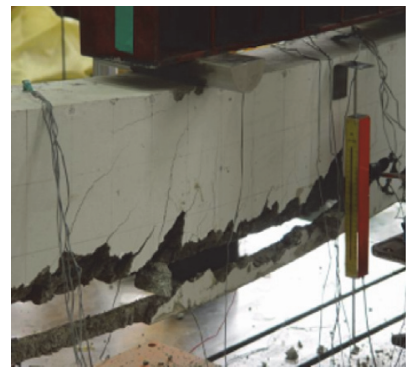

R-RD-9*2-2S

Bond failure

FIGURE 13: Failure patterns of specimens strengthened by NSMR.

The load-displacement curves were drawn using the load given by the actuator and the displacements measured by LVDTs disposed at the center and quarter points of the specimens.

\section{Results of Validation Test}

7.1. Failure Modes. Figure 13 shows the failure pattern of the specimens strengthened by NSMR. Failure occurred through rupture of CFRP or bond failure. First, the specimens that experienced CFRP rupture pertain to the specimens with relatively smaller amount of reinforcement and the specimens with trapezoidal reinforcement. In this failure mode, cracks perpendicular to the slots were observed without failure of epoxy, reinforcement, or concrete. Second, for the bond failure, cracks parallel to the slots were observed and failure of the epoxy and reinforcement occurred around the slots entraining the concrete around the slots. The occurrence of bond failure at the epoxy-concrete interface was observed not only in this study but also in most of the experimental studies related to the specimens flexure-strengthened by NSMR. The epoxy and the reinforcement are seen to behave monolithically as a unique reinforcement similarly to the failure mode (equivalent section behavior) suggested above.

In case of narrow spaced NSMR, the P-PL- $25^{*} 2-\mathrm{S}$ specimen strengthened by strip reinforcement experienced bond failure of the reinforcement and filler together with failure not only of the concrete between the slots but also of the corners. Besides, the P-RD-9*2-S specimen strengthened by rod reinforcement experienced failure of the concrete between the slots only.
In case of widely spaced NSMR, the P-PL- $25^{*} 2-2 S$ specimen strengthened by strip reinforcement experienced bond failure of the reinforcement and filler together with the quasi-disappearance of the corners. On the other hand, the P-RD-9*2-2S specimen strengthened by rod reinforcement experienced partial failure of the concrete corners due to the shock provoked by the bond failure of the reinforcement and filler.

In case of identical spacing, the different failure patterns observed according to the reinforcement can be attributed to the effect of the amount of reinforcement and moment of inertia of the cross-sectional shape.

7.2. Analysis of Strengthening Effect. Table 3 summarizes the experimental results for the specimens strengthened by NSMR. The moment, load, and deflection are represented for each instance of early cracking, rebar yielding, and maximum load. $P / P_{\text {con }}$, the load ratio of strengthened specimen to the nonstrengthened specimen (CONTROL), indicates the strengthening effect. The efficiency of CFRP is expressed in terms of the ratio of the maximum strain measured in the CFRP reinforcement of the specimen to the strain at rupture $\left(\varepsilon_{\max } / \varepsilon_{u}\right)$; as a matter of fact a ratio closer to $100 \%$ means that the reinforcement develops its best performance. In strengthening effect analysis, since the load ratio does not give information on the cross-sectional area and physical properties of the CFRP reinforcement, this indicator is valid only when the same reinforcement and strengthening method are used and not good when they are different. Accordingly, this study adopts the dimensionless strengthening effect per axial rigidity obtained by dividing the maximum load by the stiffness of the reinforcement to compare the strengthening 
TABLE 2: Material properties.

\begin{tabular}{|c|c|c|}
\hline \multirow{2}{*}{$\begin{array}{l}\text { Material } \\
\text { Concrete }^{1}\end{array}$} & \multicolumn{2}{|c|}{ Properties } \\
\hline & Compressive strength (MPa) & 31.3 \\
\hline \multirow{4}{*}{ Tension steel reinforcement $(\mathrm{D} 10)^{1}$} & Yield strength $(\mathrm{MPa})$ & 436 \\
\hline & Tensile strength $(\mathrm{MPa})$ & 562 \\
\hline & Diameter $(\mathrm{mm})$ & 9.53 \\
\hline & Area $\left(\mathrm{mm}^{2}\right)$ & 71.33 \\
\hline \multirow{4}{*}{ Compression steel reinforcement (D13) ${ }^{1}$} & Yield strength (MPa) & 481 \\
\hline & Tensile strength $(\mathrm{MPa})$ & 608 \\
\hline & Diameter $(\mathrm{mm})$ & 12.7 \\
\hline & Area $\left(\mathrm{mm}^{2}\right)$ & 126.7 \\
\hline \multirow{4}{*}{ CFRP strip (PL, smooth surface $)^{1}$} & Thickness (mm) & 1.4 \\
\hline & Tensile strength (MPa) & 2482.5 \\
\hline & Elastic modulus (GPa) & 167 \\
\hline & Ultimate strain (\%) & 1.48 \\
\hline \multirow{4}{*}{ CFRP rod (TR, smooth surface $)^{1}$} & Design thickness (mm) & 10 \\
\hline & Tensile strength (MPa) & 1500 \\
\hline & Elastic modulus (GPa) & 100 \\
\hline & Ultimate strain (\%) & 1.5 \\
\hline \multirow{4}{*}{ CFRP rod (RD, deformed surface $)^{2}$} & Diameter $(\mathrm{mm})$ & 9 \\
\hline & Tensile strength $(\mathrm{MPa})$ & 1878 \\
\hline & Elastic modulus (GPa) & 121.42 \\
\hline & Ultimate strain (\%) & 1.55 \\
\hline
\end{tabular}

1: from supplier; 2: from tests performed by authors according to [22].

effect brought by CFRP reinforcements exhibiting different sections and physical properties. Since the strengthening effect per axial rigidity $\left(P_{u} / \mathrm{EA} \times 10^{3}\right)$ considers not only the efficiency of FRP but also the physical properties of the reinforcement, this indicator becomes effective when analyzing the strengthening effect according to the strengthening method and sectional details. If the value of this indicator is high, it means that the strengthening effect is good.

The experimental results show that the yield load and maximum load increase with larger cross-sectional area of the reinforcement. However, specimens R-PL-25 and R-TR10 present identical reinforced area but different flexural behaviors. This can be explained by the fact that these two specimens have different stiffness of the reinforcements. Therefore, it appears that the comparison of the strengthening effect should consider not only the reinforced area but also the effect of the reinforcement stiffness. Accordingly, the observation of the strengthening effect per axial rigidity reveals that specimens R-TR-10 and R-PL-15 experiencing CFRP rupture have better strengthening effect than specimens $\mathrm{R}$ PL-25 and R-RD-9 featured by bond failure. In case of NSMR using reinforcements with identical shape, the strengthening effect per axial rigidity tends to reduce with larger amount of reinforcement. The reduction of the strengthening effect per axial rigidity even if the reinforced area increases as much as the increase of the amount of reinforcement can be attributed to the fact that the reinforcement could not develop $100 \%$ of its performance due to bond failure. Such tendency is more apparent in the specimens strengthened by 2 lines of reinforcement and seems to be caused by the premature occurrence of bond failure following the overlapping of the failed surfaces.

The comparison of the strengthening effects brought by 1-line and 2-line reinforcement shows that the strengthening effects of specimens R-PL- $25^{*} 2-\mathrm{S}$ and R-PL-25*2-2S reach, respectively, $69 \%$ and $75 \%$ which is lower than the $83 \%$ of specimen R-PL-25 with 1-line reinforcement. Moreover, specimen R-PL-25*2-S with smaller spacing than specimen R-PL-25*2-2S is more vulnerable to failure. Specimen R-RD$9^{*} 2$-S with round reinforcement and narrow spacing shows reduced strengthening effect compared to the specimens with 1-line reinforcement and indicates that the failure of the slot spacing affects the bond failure. The strengthening effect of specimen R-RD-9*2-2S with large spacing reaches $91 \%$, which is higher than the specimens with 1-line reinforcement and indicates that this specimen is less influenced by the spacing. Failure modes are affected by the position of slots when the distance between slots or the distance from slot to corner is less than $40 \mathrm{~mm}$ [21]. R-PL- $25^{*} 2-\mathrm{S} / 2 \mathrm{~S}$ specimens have $40 \mathrm{~mm}$ space between slots and corner and therefore one slot's failure affects the other slots' failure and corners. The comparison of strengthening effects per axial rigidity shows that R-PL-25*2-S specimen is larger than R-RD-9*2-S specimen because the distance between slots of R-PL-25*2-S specimen is wider than that of R-RD-9*2-S specimen.

7.3. Comparison of Experimental and Analytical Results. Figure 14 plots concurrently the load-displacement curve measured at midspan and the analytical values derived from the analytic model of this study together with the failure 


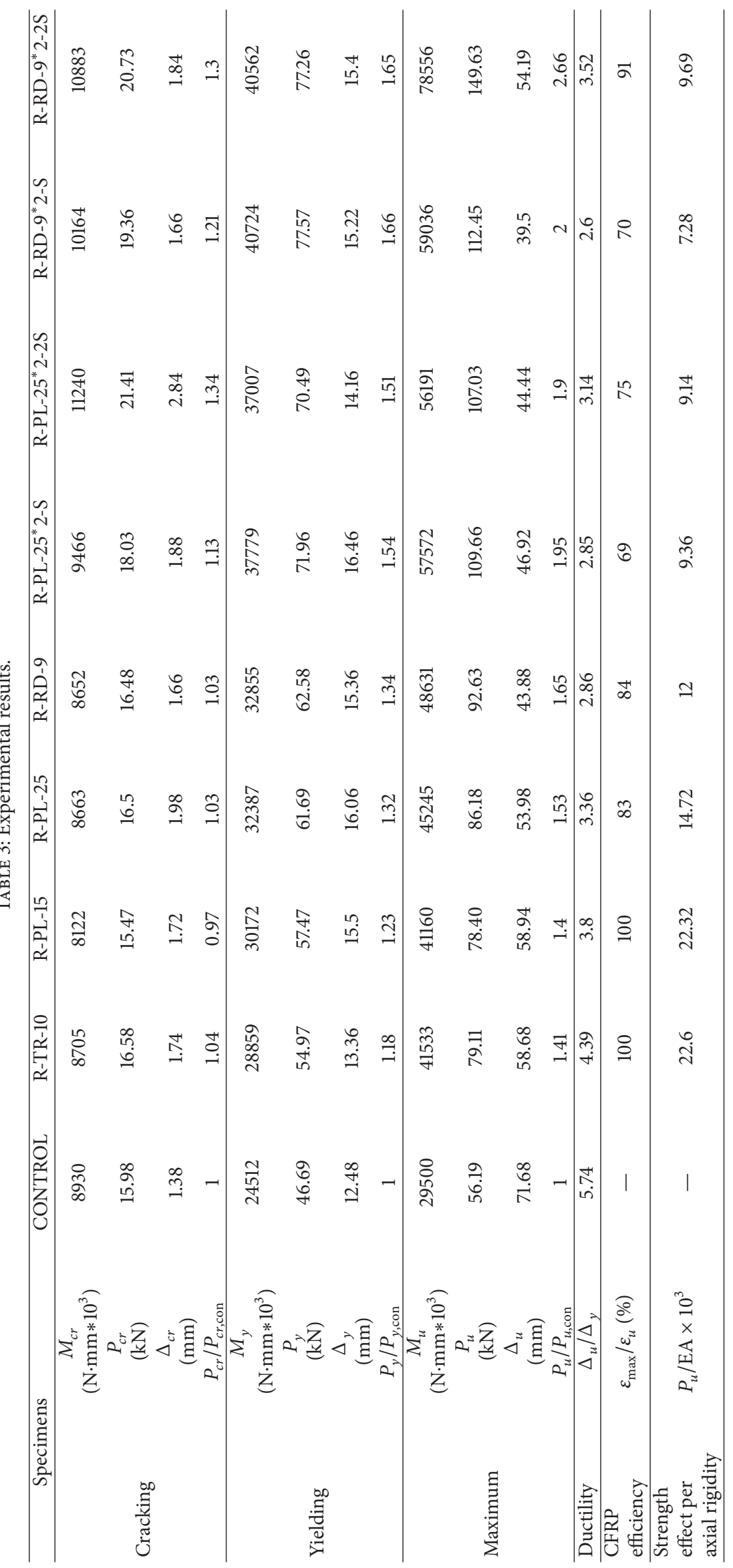



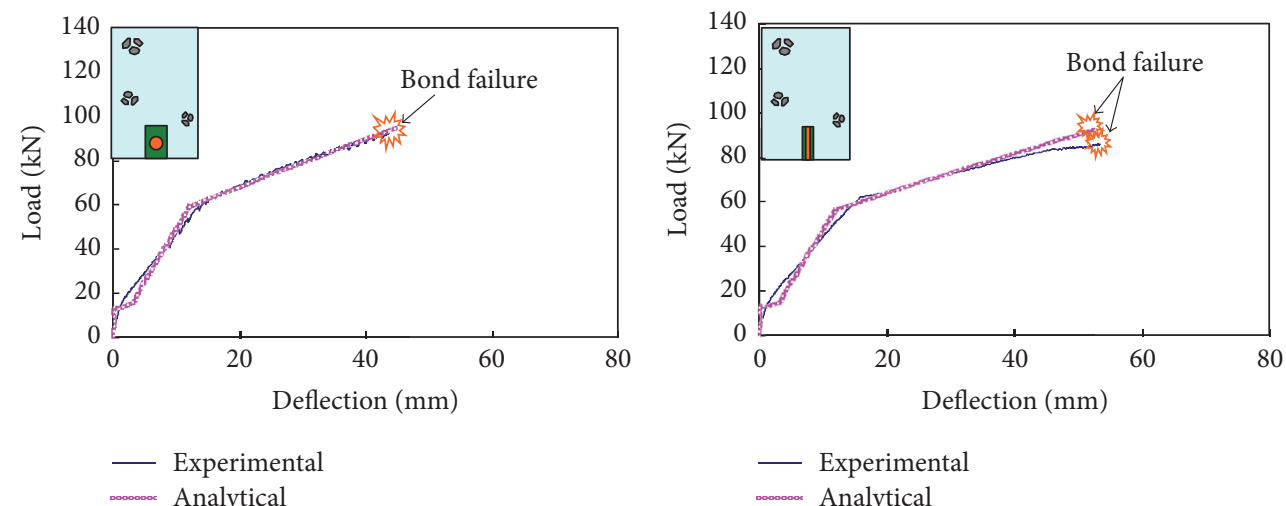

- Experimenta

soosoos Analytical

(a) R-RD-9

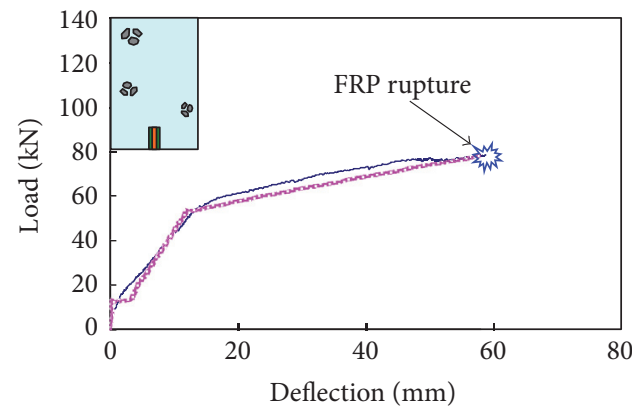

(b) R-PL-25

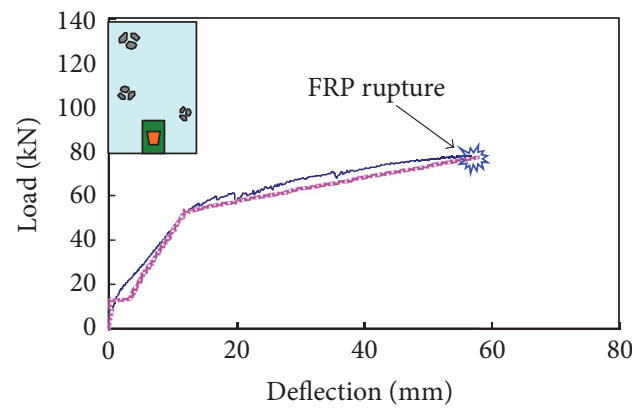

- Experimental

soosoosoc Analytical

- Experimental

sansosese Analytical

(c) R-PL-15

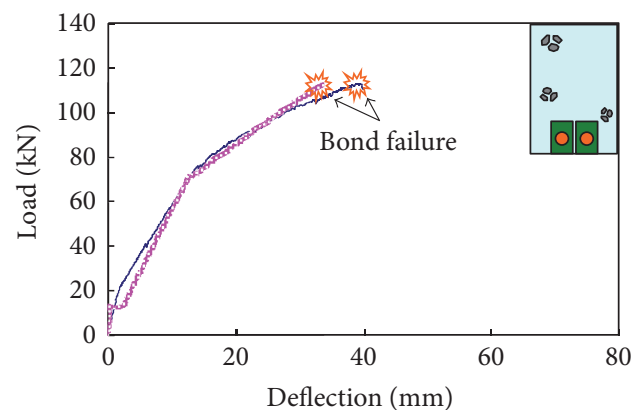

(d) R-TR-10

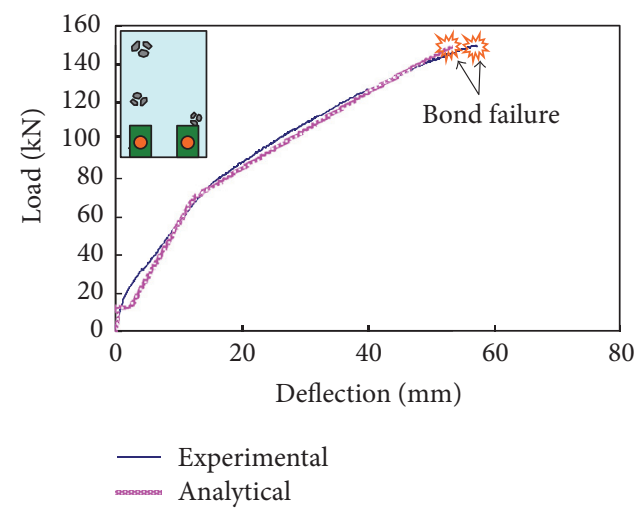

(f) R-RD-9*2-2S

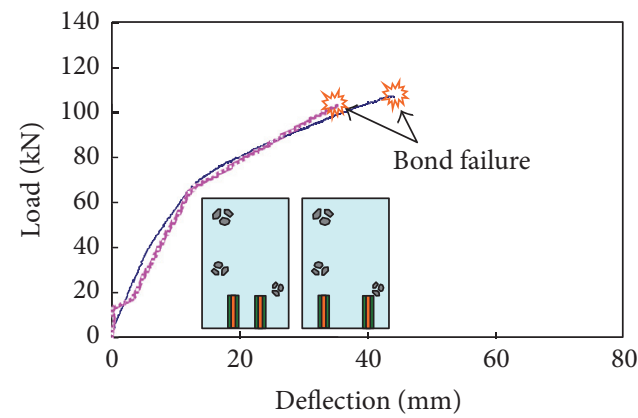

- Experimental

(00000000 Analytical

(g) R-PL-25*2-S(2S)

FIGURE 14: Comparison of experimental and analytical load-deflection curves. 
TABLE 4: Comparison of experimental and analytical results.

\begin{tabular}{|c|c|c|c|c|c|c|c|c|c|}
\hline \multicolumn{2}{|c|}{ Specimens } & R-TR-10 & R-PL-15 & R-PL-25 & R-RD-9 & R-PL-25*2-S & R-PL-25*2-2S & R-RD-9*2-S & R-RD-9*2-2S \\
\hline \multirow{3}{*}{$\begin{array}{l}\text { Moment at } \\
\text { yielding } \\
(\mathrm{kN} \cdot \mathrm{mm})\end{array}$} & Test & 28859 & 30172 & 32855 & 32387 & 37779 & 37007 & 40724 & 40562 \\
\hline & Analysis & 27698 & 27783 & 30821 & 29667 & 34198 & 34198 & 36480 & 36480 \\
\hline & Analysis/test & 1.04 & 1.09 & 1.07 & 1.09 & 1.10 & 1.08 & 1.12 & 1.11 \\
\hline \multirow{3}{*}{$\begin{array}{l}\text { Maximum } \\
\text { moment } \\
(\mathrm{kN} \cdot \mathrm{mm})\end{array}$} & Test & 41533 & 41160 & 48631 & 45245 & 57572 & 56191 & 59036 & 78556 \\
\hline & Analysis & 40613 & 41054 & 49652 & 48584 & 54259 & 54259 & 59089 & 78372 \\
\hline & Analysis/test & 1.02 & 1 & 0.98 & 0.93 & 1.06 & 1.04 & 1 & 1 \\
\hline \multirow{3}{*}{$\begin{array}{l}\text { Deflection at } \\
\text { yielding } \\
(\mathrm{mm})\end{array}$} & Test & 13.36 & 15.5 & 15.36 & 16.06 & 16.46 & 14.16 & 15.22 & 15.4 \\
\hline & Analysis & 11.96 & 11.96 & 12.1 & 12.04 & 12.24 & 12.24 & 12.35 & 12.35 \\
\hline & Analysis/test & 1.12 & 1.3 & 1.27 & 1.33 & 1.34 & 1.16 & 1.23 & 1.25 \\
\hline \multirow{3}{*}{$\begin{array}{l}\text { Maximum } \\
\text { deflection } \\
(\mathrm{mm})\end{array}$} & Test & 58.68 & 58.94 & 43.88 & 53.98 & 46.92 & 44.44 & 39.5 & 54.19 \\
\hline & Analysis & 57.83 & 57.85 & 44.78 & 52.56 & 35.16 & 35.16 & 33.53 & 53.39 \\
\hline & Analysis/test & 1.01 & 1.02 & 0.98 & 1.03 & 1.33 & 1.26 & 1.18 & 1.02 \\
\hline
\end{tabular}

mode. Table 4 compares the experimental and analytical values of the moment and displacement at each stage. The analytic model proposed in this study is seen to predict the experimental maximum load within an error of $8 \%$ for all strengthened beams and shows perfect concordance with the final failure mode. The analysis of the specimens strengthened with 1-line reinforcement applied the bond failure model I. Among the specimens strengthened with 2-line reinforcement, for the cases where failure occurred between the slots (Figure 14(e)) and the cases experiencing failure between the slots and additional failure of the concrete corners (Figure 14(g)), analysis was performed using the bond failure model II-2 simplifying the failure mode. For the specimens that experienced failure of the concrete corners (Figure 14(f)), the bond failure model II-1 was applied in the analysis similarly to the 1-line failure mode.

In view of the analytical results, the bond failure model proposed in this study appears to predict accurately the failure mode of the 1-line NSMR as well as of the 2-line NSMR specimens and to simulate appropriately the loaddisplacement behavior.

\section{Conclusions}

This study examined the failure modes reported in previous studies to propose a bond failure model considering the equivalent section. Tests were performed on specimens strengthened by NMSR with various shapes of CFRP reinforcement. The following conclusions can be drawn.

The survey of the failure modes observed in former specimens flexure-strengthened by NSMR revealed that failure occurred mainly through rupture of CFRP reinforcement, failure of filler-concrete interface, and failure of filler-CFRP reinforcement interface with larger occurrence of the failure of filler-concrete interface than the failure of filler-CFRP reinforcement interface.

Based upon this inventory of the major failure modes of the flexure-strengthened specimens, the failed surface was assumed as an equivalent section representing the fillerconcrete interface and a bond failure model was derived so as to be applicable regardless of the sectional shape of the CFRP reinforcement.

Tests were then conducted on flexure-strengthened specimens by NSMR to validate the proposed bond failure model. The experimental results showed that the yield load and maximum load increased with larger cross-sectional area of the CFRP reinforcement and that the strengthening effect per axial rigidity reduced even if the bonded area enlarged as much as the increase of the amount of reinforcement. This was explained by the fact that the reinforcement could not develop $100 \%$ of its performance due to bond failure.

In the case of the specimens strengthened with 2-line reinforcement, premature bond failure occurred due to the overlapping of the failed surface caused by the reinforcement spacing. Accordingly, further studies should be conducted on the details of the reinforced section to compute the minimum spacing enabling the slots to behave independently during the NSMR design.

Analytical analysis was finally carried out by setting failure criteria for the bond failure model considering the equivalent section proposed in this study. The results validated the failure mode in which the CFRP reinforcement and filler behaved monolithically and regardless of the sectional shape of the CFRP reinforcement. Moreover, the failure mode and flexure-strengthened behavior could be predicted within an error of $8 \%$.

\section{Competing Interests}

The authors declare that they have no competing interests.

\section{Acknowledgments}

This research was supported by a grant from "A Strategic Research Project Funded by the Korea Institute of Civil Engineering and Building Technology" and "Upgrading 
Technology of Prestressed NSM Reinforcement System with CFRP Tendon."

\section{References}

[1] W. T. Jung, Flexural behavior of reinforced concrete beams strengthened with NSM CFRP reinforcements considering the equivalent section [Ph.D. thesis], Myongji University, Seoul, South Korea, 2009.

[2] R. EI-Hacha, "Effectiveness of near surface mounted FRP reinforcement for flexural strengthening of reinforced concrete beams," in Proceedings of the 4th International Conference on Advanced Composite Materials in Bridges and Structures, Alberta, Canada, July 2004.

[3] KICT, Development of Strengthening Methods for Deteriorated Concrete Bridges, Report, 2004.

[4] L. De Lorenzis and J. G. Teng, "Near-surface mounted FRP reinforcement: an emerging technique for strengthening structures," Composites Part B: Engineering, vol. 38, no. 2, pp. 119-143, 2007.

[5] T. Hassan and S. Rizkalla, "Investigation of bond in concrete structures strengthened with near surface mounted carbon fiber reinforced polymer strips," Journal of Composites for Construction, vol. 7, no. 3, pp. 248-257, 2003.

[6] T. Hassan and S. H. Rizkalla, "Bond mechanism of nearsurface-mounted fiber-reinforced polymer bars for flexural strengthening of concrete structures," ACI Structural Journal, vol. 101, no. 6, pp. 830-839, 2004.

[7] I. Del Prete, A. Bilotta, L. Bisby, and E. Nigro, "Bond tests on NSM FRP strengthening using cementitious matrices for concrete structures," in Proceedings of the 4 Contributo in Atti di Convegno, FRPRCS-12 \& APFIS-2015 Joint Conference, 2015.

[8] M. R. F. Coelho, J. M. Sena-Cruz, and L. A. C. Neves, "A review on the bond behavior of FRP NSM systems in concrete," Construction and Building Materials, vol. 93, pp. 1157-1169, 2015.

[9] A. M. Malek, H. Saadatmanesh, and M. R. Ehsani, "Prediction of failure load of R/C beams strengthened with FRP plate due to stress concentration at the plate end," ACI Structural Journal, vol. 95, no. 2, pp. 142-152, 1998.

[10] I. A. Sharaky, L. Torres, J. Comas, and C. Barris, "Flexural response of reinforced concrete (RC) beams strengthened with near surface mounted (NSM) fibre reinforced polymer (FRP) bars," Composite Structures, vol. 109, no. 1, pp. 8-22, 2014.

[11] S. A. Mirza, M. Hatzinikolas, and J. G. MacGregor, "Statistical descriptions of strength of concrete," ASCE J Struct Div, vol. 105, no. 6, pp. 1021-1037, 1979.

[12] G. Tumialan, P. Serra, A. Nanni, and A. Belarbi, "Concrete cover delamination in RC beams strengthened with FRP sheets, SP-188," in Proceedings of the 4th International Symposium on FRP for Reinforcement of Concrete Structures (FRPRCS4 '99), pp. 725-735, American Concrete Institute, Baltimore, Md, USA, November 1999.

[13] U. Neubauer and F. S. Rostasy, "Design aspects of concrete structures strengthened with externally bonded CFRP plates," in Proceedings of the 7th International Conference on Structural Faults and Repairs, vol. 2, pp. 109-118, ECS Publications, Edinburgh, UK, 1997.

[14] J. S. Park, Flexural behavior of RC beam strengthened with prestressed CFRP plates considering bond characteristics [Ph.D. thesis], Myongji University, Seoul, Republic of Korea, 2007.
[15] ACI Committee 318, Building Code Requirements for Structural Concrete (318-05) and Commentary-(318R-05), American Concrete Institute, 2005.

[16] M. P. Collins and D. Mitchell, Prestressed Concrete Structures, Prentice Hall, 1991.

[17] H. E.-D. M. Sallam, A.-A. M. Saba, H. H. Shahin, and H. AbdelRaouf, "Prevention of peeling failure in plated beams," Journal of Advanced Concrete Technology, vol. 2, no. 3, pp. 419-429, 2004.

[18] S. B. Lee, M. Y. Park, S. Y. Jang, K. S. Kim, and S. S. Kim, "Investigation on the effective moment of inertia of reinforced concrete flexural members under service load," Journal of the Korea Concrete Institute, vol. 20, no. 3, pp. 393-404, 2008.

[19] D. E. Branson, "Instantaneous and time-dependent deflections of simple and continuous reinforced concrete beams," HPR Report 7, part 1, Alabama Highway Department; Bureau of Public Roads, 1963.

[20] J. Y. Park, H. D. Cho, and S. H. Han, "Prediction of non-linear behavior for RC beam flexural strengthened with CFRP plate," KSCE Journal of Civil Engineering, vol. 24, no. 1, pp. 9-16, 2004.

[21] J. Y. Kang, Y. H. Park, J. S. Park, Y. J. You, and W. T. Jung, "Analytical evaluation of RC beams strengthened with near surface mounted CFRP laminates," in Proceedings of the 7th International Symposium on Fiber-Reinforced Polymer Reinforcement for Reinforced Concrete Structures (FRPRCS '05), November 2005.

[22] ACI 440.3R-04, "Guide test methods for fiber-reinforced polymer(FRPs) for reinforcing and strengthening concrete structures," American Concrete Institute, 2004.

[23] J. A. O. Barros and A. S. Fortes, "Flexural strengthening of concrete beams with CFRP laminates bonded into slits," Cement and Concrete Composites, vol. 27, no. 4, pp. 471-480, 2005.

[24] R. El-Hacha and S. H. Rizkalla, "Near-surface-mounted fiberreinforced polymer reinforcements for flexural strengthening of concrete structures," ACI Structural Journal, vol. 101, no. 5, pp. 717-726, 2004.

[25] A. Carolin, B. Täljsten, and A. Hejll, "Concrete beams exposed to live loading during carbon fiber reinforced polymer strengthening," Journal of Composites for Construction, vol. 9, no. 2, pp. 178-186, 2005.

[26] J. G. Teng, L. De Lorenzis, B. Wang, R. Li, T. N. Wong, and L. Lam, "Debonding failures of RC beams strengthened with near surface mounted CFRP strips," Journal of Composites for Construction, vol. 10, no. 2, pp. 92-105, 2006.

[27] J. A. O. Barros, S. J. E. Dias, and J. L. T. Lima, "Efficacy of CFRPbased techniques for the flexural and shear strengthening of concrete beams," Cement and Concrete Composites, vol. 29, no. 3, pp. 203-217, 2007.

[28] J. R. Yost, S. P. Gross, D. W. Dinehart, and J. J. Mildenberg, "Flexural behavior of concrete beams strengthened with nearsurface-mounted CFRP strips," ACI Structural Journal, vol. 104, no. 4, pp. 430-437, 2007.

[29] H. Nordin and B. Täljsten, "Concrete beams strengthened with prestressed near surface mounted CFRP," Journal of Composites for Construction, vol. 10, no. 1, pp. 60-68, 2006.

[30] H. T. Choi, J. S. West, and K. A. Soudki, "Partially bonded near-surface-mounted CFRP bars for strengthened concrete Tbeams," Construction and Building Materials, vol. 25, no. 5, pp. 2441-2449, 2011.

[31] A. M. Khalifa, "Flexural performance of RC beams strengthened with near surface mounted CFRP strips," Alexandria Engineering Journal, vol. 55, no. 2, pp. 1497-1505, 2016. 
[32] S. E. El-Gamal, A. Al-Nuaimi, A. Al-Saidy, and A. Al-Lawati, "Efficiency of near surface mounted technique using fiber reinforced polymers for the flexural strengthening of RC beams," Construction and Building Materials, vol. 118, pp. 52-62, 2016.

[33] S.-Y. Seo, K.-B. Choi, Y.-S. Kwon, and K.-S. Lee, "Flexural strength of rc beam strengthened by partially de-bonded near surface-mounted FRP Strip," International Journal of Concrete Structures and Materials, vol. 10, no. 2, pp. 149-161, 2016.

[34] S. Foubert, K. Mahmoud, and E. El-Salakawy, "Behavior of prestressed hollow-core slabs strengthened in flexure with nearsurface mounted carbon fiber-reinforced polymer reinforcement," ASCE Composite Construction Journal, vol. 20, no. 6, 2016.

[35] A. Bilotta, F. Ceroni, E. Nigro, and M. Pecce, "Efficiency of CFRP NSM strips and EBR plates for flexural strengthening of RC beams and loading pattern influence," Composite Structures, vol. 124, pp. 163-175, 2015.

[36] A. A. Khalil, E. E. Etman, and A. H. El-Masry, "Behavior of reinforced concrete continuous beams strenghened with near surface mounted reinforcement," in Proceedings of the International Conference on Advances in Structural and Geotechnical Engineering, Hurghada, Egypt, April 2015.

[37] H. Zhang, L. He, and G. Li, "Bond failure performances between near-surface mounted FRP bars and concrete for flexural strengthening concrete structures," Engineering Failure Analysis, vol. 56, pp. 39-50, 2015.

[38] B. Almassri, A. Kreit, F. A. Mahmoud, and R. François, "Mechanical behaviour of corroded RC beams strengthened by NSM CFRP rods," Composites Part B: Engineering, vol. 64, pp. 97-107, 2014.

[39] W. Ibrahim, W. A. Fattah, A. Kotb, and M. A. Mjeed, "Flexural behavior of RC beams strengthened with CFRP strips," in Proceedings of the 7th International Conference on FRP Composites in Civil Engineering (CICE '14), Canada, August 2014.

[40] A. Laraba, N. Chikh, H. Mesbah, N. Djebbar, and A. Belouar, "Experimental evaluation of damaged rectangular reinforced concrete beams repaired with near surface mounted carbon fibre reinforced polymer," Materials Research Innovations, vol. 18, no. 6, pp. S6-S13, 2014. 

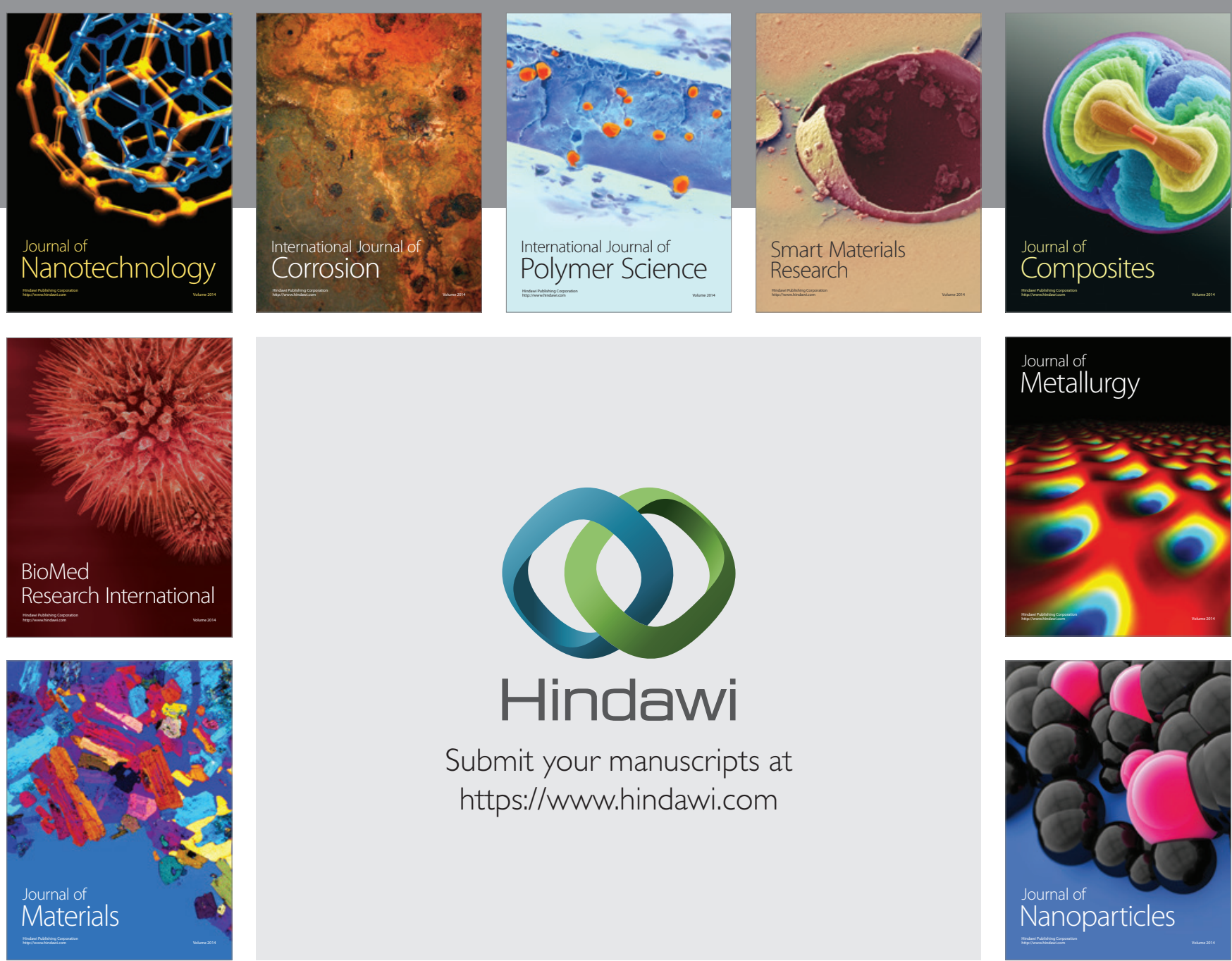

\section{Hindawi}

Submit your manuscripts at

https://www.hindawi.com

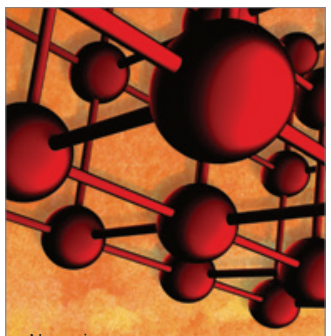

Materials Science and Engineering
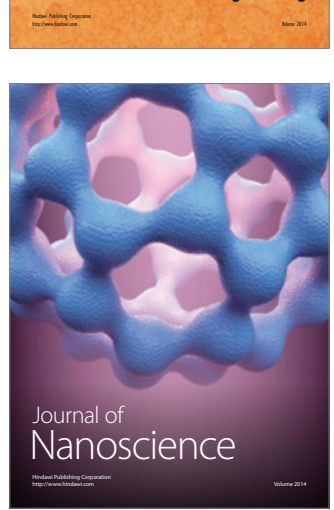
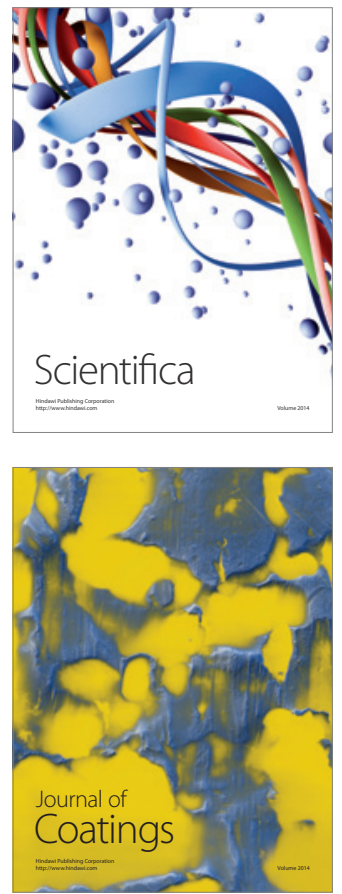
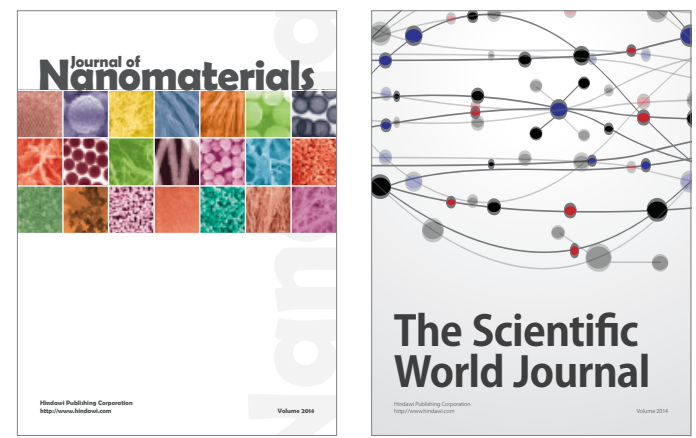

The Scientific World Journal
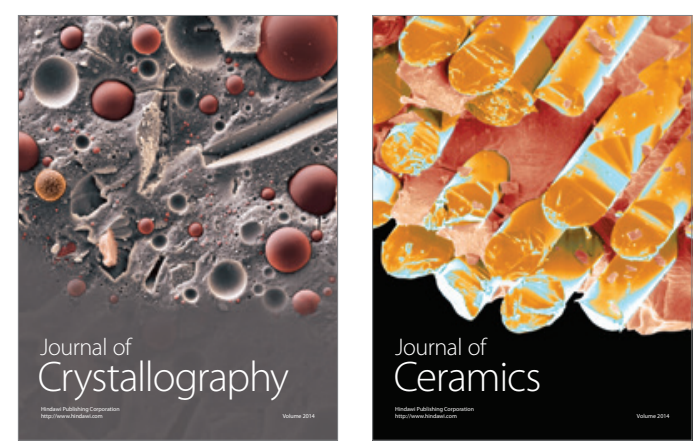
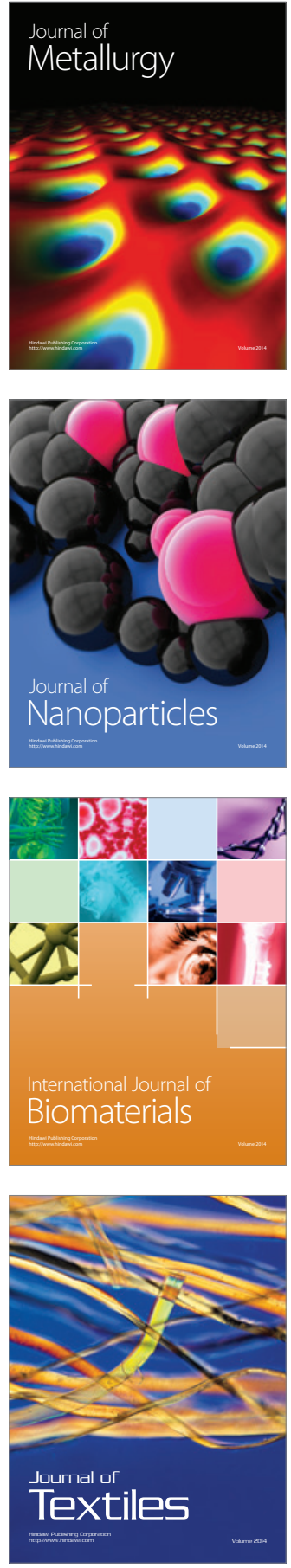